\title{
Shape-Shifting Sources and Illusory Targets: Jhaverchand Meghani and Saurashtrani Rasdhar
}

\author{
KRUPA SHAH
}

\begin{abstract}
This paper challenges the static notions of a 'source text', fixed and 'bordered' in language and time, and serving as the prototype for a translation that is always and inevitably seen to take place in a cultural 'elsewhere'. It explores instead the source and the target not as binaries separated by cultural and linguistic borders, but as a spectrum, one conflating into the other. This model of thought is particularly helpful in the context of the Gujarati writer Jhaverchand Meghani (1897- 1947) who was a prolific writer, critic and journalist. This paper limits itself to the context of his pioneering work in Gujarati folk literature, especially a collection of lokavarta or folk stories about the Rajput life and valour in medieval Saurashtra called Saurashtrani Rashdhar. Meghani travelled far and wide in Saurashtra over a period of several years collecting and documenting repositories of oral culture through folk stories, songs, ballads and various other popular forms. His sources were people from various occupations, castes, gender and class. Sometimes there was more than one version of the same tale and sometimes the same story contained idioms of two languages of regions that were linguistically similar, like Kutch and
\end{abstract}


Kathiawad. How does one think of borders and sources in these contexts? This paper looks at a number of such consequences in the context of Meghani's folk stories and examines sites of translational borders and exchanges in order to propose a new way of thinking about sources and targets.

Keywords: Shape-shifting Sources, Illusory Targets, Meghani, Saurashtrani Rasdhar, Translation and Borders.

\section{Introduction: Translation and Borders}

Notions of translation as they have been traditionally conceived of, speak of translation as a process predicated on displacement; a movement from one cultural, social, textual, linguistic environment to another. An oft used metaphor is one of transference or the transplanting of a text from one linguistic terrain into another semantic field. This notion of translation has operated squarely on the duality of the self and the other, the original and the derivative, the essence and the dilution and so on, and is inescapably founded on difference and separation. This discrimination has also served, as Venuti reminds us, to legitimize the writer's creativity while confounding the translator to invisibility. The idea of translation as displacement is also etymologically verified with the word's Latin root 'trans-latus' that refers to 'carrying across'. While translation etymologically inscribes the notion of borders within itself (trans-latus) it also involves an encounter with the other by movement. In a way this ambivalence resonates with the simultaneity of the border itself as confinement as well as site of exchange. It is also indicative of the possibility of spaces of liminality inherent in 
both boundaries and acts of translation that enable alternative mappings of conflicted terrains.

Edwin Gentzler (2014) argues that while it is easier to move across traditional borders today, new borders are constantly created and drawn through emerging connections "between and among regional ethnic groups, professional associations, different races, genders, language minorities, communities, neighbourhoods, and generations. As individuals constantly traverse these multiple and increasing microborders, definitions of nations or nation-states are changing, and so too are definitions of language and translation". In such a situation, asks Gentzler, is it not possible to rethink translation "not as a product-a translated text-nor a process - a carrying/ferrying a text across a divide" but as "an always ongoing process of every communication? [...] not a speech-act carried out between languages and cultures, but instead a condition underlying the languages and cultures upon which communication is based". This notion of translation is not limited to the process of change from source to target but constitutes them both in the first place. The source and target are themselves always and already in-translation and hence the very categories of 'source' and 'target' do not hold. Instead I draw from Merrill (2009) and her reading of the term 'anuvad' as telling in turn, in order to see oral narratives as tellings rather than as source or target 'texts'.

The metaphor of the border has come to be invested with multiple meanings from multiple cultural and literary standpoints. It has most prominently gained acceptance in the context of strategies of decoloniality evolved by Latin American thinkers such as Walter Mignolo and Gloria Anzaldua among many others. Mignolo's concept of border thinking for example, stresses 'reversing the geography of 
reason' by delinking from the modernity-coloniality matrix. Border living and thinking becomes a decolonial strategy for epistemological reconstitution as it provides a space for alternative ways of knowing and being to be crafted from reserves of native experience. Preyer and Bos (2013) discuss notions of border and membership put forth by Georg Simmel who sees borders not as spatial demarcations but as sociological facts that promote a sense of coherence through relationships of membership. Luhmann on the other hand, considers the border not as a line but as a membrane that enables exchange and interaction and connects a system with the environment (ibid.). For the scope of this paper, I draw from Preyer and Bos who take on both these ideas in a discussion centred on borders in the context of the conflicting tensions of globalisation: "Border structures are dynamic processes of connection and separation, be it the line or the membrane, there is always a three-way logic of borders: borders include, exclude and connect at the same time" (ibid.).

Drawing from this definition of dynamic borders and Genztler's idea of what I call 'dynamic translation', this paper examines Jhaverchand Meghani's Saurashtrani Rasdhar (1923-27) as an instance of unbordered tellings made possible through motile and plurally possessed 'sources.'

\section{Meghani and Rasdhar: Context}

Saurashtra is the name of the Southeastern peninsular region of Gujarat which takes its other name Kathiawad from the Kathi rulers who ruled parts of it in the 18th century (Desai 5). Saurashtrani Rasdhar (1923-27) or A Noble Heritage: A Collection of Short Stories based on the Folklore of Saurashtra as it was called by Vinod Meghani in his English translation, is an exhaustive and unique treasure trove of folk stories intended 
to show the brave and noble culture of the Rajput age of medieval Saurashtra (A.D. 875-1472). Its stories were collected from various sources and written and edited by Jhaverchand Meghani, a prolific journalist and writer, a pioneer in the field of Loksahitya and known by the celebrated appellation of 'Rashtriya Shayar' or 'National Poet' by Gandhi. In his preface, Meghani describes his collection as an attempt to redress the stereotype of Kathiawad as a land without cultural heritage and barren of literary inspiration (2014: 11). Meghani attempts to acquaint the reader with the land of Saurashtra through a rich palimpsest of more than a hundred folk stories of characters from various communities such as the Ahiyars, the Charans, the Bhils, the Mers among many others and recounts tales scattered over diverse locales ranging from the banks of the Shetrunji river, the hilly terrains of Kanado and Girnar in the South, sometimes meandering through remote and obscure villages including the proverbial Limadi and sometimes weaving through centres of mainstream life such as Ahmedabad or Vadodara which appear most often as places of employment and prosperity.

Apart from various communities, there are also characters from various classes and occupations much like the people from whom Meghani heard and wrote down these stories. The stories are boisterously populated with kings, queens, ordinary village folk, stingy Vaniyas and loyal Arabs, dauntless Rajputs, waylaying bandits and friends who forgive each other for terrible sins, lovers wrecked by envy and malice; women appear in various avatars, sometimes as bold Rajputanis fighting to their last breath, sometimes as victims of patriarchy exchanged like commodities among families. With such a rich tapestry of images and glimpses of what was then a hundred year old glorious past, Saurashtrani Rasdhar was an important intervention in the historiography of Kathiawad as well as in 
its social imagination. It was also in many ways an important literary means to create a discourse of the past not just to claim a historical space but to breathe life into a sense of regional pride for Kathiawadi culture and identity even for future generations. As Meghani writes:

One who resides in Saurashtra will be able to go among any worshipper of culture and tell him proudly: My land has witnessed events that are comparable to the chronicles of England, Greece and Rome and that is why I ask to claim a space for that glorious past [...] -not in the voice of a supplicant, but full-throated as one who demands his right.

(Meghani P., jhaverchandmeghani.com).

In Saurashtrani Rasdhar, 'rasdhar,' a word coined by Meghani brings together 'rasa' and 'dhar' to mean a sense of heritage. Dhar can mean a stream, an edge and conveys both a sense of dynamic continuity as well as a firm sense of foundation as suggested by the similar word 'aadhar.' The word 'rasa' poses a significant issue for the translator as it has at least seven meanings in Gujarati. Among the variant ones, 'rasa' can mean juice, nectar, essence or flavour and also 'mood' along the rules of classical poetry which consists of the nava rasas. While the Rasdhar embodies all these nuances, it is also fitting that Meghani, as a writer of the people and an upholder of 'the Desi' instead of the 'Marga' tradition, uses this double entendre in naming a collection of work that is not about classical literature but about what A. K. Ramanujan has called the "literature of the dialects, those mother tongues of the village, street, kitchen, tribal hut, and wayside tea shop [...] the wide base of the Indian pyramid on which all other Indian literatures rest" (4). It is clear that Meghani plays with these meanings even as his five-volume collection of stories has a 
separate index that classifies all the stories along certain qualities: Sauryakatho (stories of valour), Dilavarini Kathao (stories of large-heartedness), Sheel ane Swarpanni Kathao (stories of temperance and self-sacrifice), Premkathao (love stories). That the qualities of valour, generosity, temperance and self-sacrifice are qualities that best exhibit the true culture of Kathiawad to the unfamiliar reader is also significant for the nationalist context of the early twentieth century. On reading the Rasdhar, R. V. Pathak, a prominent writer and critic of the time wrote that the purpose of the stories was to acquaint readers with "lokswabhav" or the "nature of the popular" in emotive and expressive modes particular to the common man. $\mathrm{He}$ also points out that such stories and the qualities present in them such as heroism, the empowerment of women and virtuousness were all relevant for the present society which had lost its vigour (Doshi 2002: 217). Thus, what Meghani had intended to create at the level of a regional consciousness lent itself almost seamlessly for the cause of nationalism.

\section{Shape-Shifting Sources}

Meghani,"a child of the mountains of Saurashtra", as he called himself, travelled far and wide in over a period of 9 to 10 years collecting and documenting repositories of oral culture through folk stories, songs, ballads and various other forms of popular memory. He wrote these down in bits and pieces as he encountered them in all the variety of linguistic regional inflections spanning rural dialects of Sorathi, Kutchi among dozens of other variations and all these interwoven in the end with his own knowledge of chaste or shisht scholarly Gujarati. In addition to this linguistic confluence, he himself simultaneously worked as a journalist, editor, and writer as he wrote for the recently established journal Saurashtra on a few days of the week and took to travelling and collecting folktales 
on other days. The notes he took were then freely edited, extended, rewritten into the final form of the stories of Rasdhar. Other insertions into the tale included details of location, time of the event and dialogue in order to create the sense of an oral narration in the written form (Doshi 220). This process of rewriting, editing and shaping the story out of a lokvarta that has elements of music, repetition and improvisation in its narrative constitute a number of translational changes on the sites of language, orality and form.

To illustrate the issue of language, when Meghani's first attempt at collecting, correcting stories from Saurashtra was published and brought him fame, Sundaram, a well-known poet and writer at that time, criticized the register of the language and found it to be refined with each edition:

One does not hear this kind of language from a Charan. [ ...] The stories of Rasdhar are beginning to be cast in the mould of our 'Shisht' Gujarati and this is why they are losing their singularity. I am afraid that in the days to come these stories will only be read and would have lost their oral potential (ibid.).

Sundaram further points out that "when a story remains circulating through orality, the problem of the 'correct register' does not arise. But when it is put down on paper, it falls unwittingly into this trap" (ibid.). This comment was taken so seriously by Meghani that the next volume of stories that came out had a distinctly Sorathi touch, with phrases and words left intact. He also included a glossary of terms and explanations in Gujarati for readers unfamiliar with certain terms of phrases and usages of Kathiawadi. One can clearly see that the problem that Sundaram was talking about was essentially a problem of translation and orality. Yet, the Rasdhar is not 
merely a literary attempt at 'translating' a rural repository of oral traditions into 'urban' forms of language. The dichotomies of oral, print, rural, urban, pre-modern, modern and so on risk the danger of drawing unequal and inaccurate relations between the two. Many scholars have already laid bare the intellectual fallacies in conceiving the folk as primarily oral, pre-modern and a marker of a so-called rural mode of experience and memory. Let us look at some of these conceptions.

\section{Theorizing Orality}

Several scholars have grappled with a meaningful understanding of the orality of narrative traditions. Linda Hess, in the context of the study of Kabir oral traditions, observes that one of the great features of orality is that it is embodied (Hess 2015: 1). It deals with more than words and comes from the corporeal moorings of a speaker and listener both engaged bodily and mentally in the same space and time. These performative exchanges of meaning-making and interpretation cannot operate without context. And each context is as integral to a telling as is its own message. By conceiving of orality outside the mechanism of the text "that holds its own shape" (ibid, 4), orality becomes not only a contextualised expressive mode but equally a domain of collective and individual experience.

Conventional notions of orality have dwelt upon fluidity as opposed to the fixity of the written letter as a primary feature of orality. But such polarisation is a fallacy as the written and the oral exist in tandem. Devy (2010) argues that literature and what he calls 'orature' are both overlapping linguistic manifestations of a society's creative imagination. [...] A close analysis of any significant 'written' work of 
literature will indicate that it has internalized and consciously foregrounded features of 'spoken' language, such as speech rhythms, conversational tones and musical tonality, dialects and regional styles. Similarly, no composition belonging to a given oral tradition is free of linguistic self-consciousness; and devices serving to aid memory, such as pauses and stops or 'punctuation', allusions to earlier compositions and texts, and even stylistic clues that help in exploration of the authorial imagination are all features of written literature (30).

Furthermore, the conception of orality as a bounded phenomenon anchored in rural or popular modes of expression implies a romantic view of the rural and risks the danger of pitting its perceived 'impoliteness' against the metallic excesses of the city. Scholar like A. K Ramanujan has convincingly observed:

"Folk texts are pervasive, behind, under, around all the texts of our society, and in all its strata, not merely among the rural and the illiterate, the "unreflective many." City and village, factory and kitchen, Hindu, Buddhist, and Jaina, Christian, and Muslim, king, priest, and clown, the crumbling almanac and the runaway computer - all are permeated by oral traditions, tales, jokes, beliefs, and rules of thumb not yet found in books".

Consequently, the trope of speaking that Merrill (2009) alludes to becomes an important aspect of orality in challenging not only the notion of text as written property, but also in unsettling anxieties about origin. Each telling becomes as valid as another, each version of a story as legitimate as another. The question that belies this situation is not then of 
the authentic text, but of what each version itself points to and the contexts that it harbours and consists of.

More recently, scholars like Francesca Orsini and Katherine Butler Schofield have turned their attention to theorizing "the deep interdependencies of written text, sound, performer, audience and meaning" in order to study orality as part of "a cultural and literary field that can be mapped historically" (2015: 4).

Furthermore, there is no one form of a story, no one version. Meghani's sources were people from various occupations, castes, gender and class. Sometimes there was more than one version of the same tale as in the case of a story called Hothal that has versions in both Kathiawad and Kutch. Which would be the original and what would be the source text? If a folktale can be defined as "a poetic text that carries some of its cultural contexts within it; it is also a travelling metaphor that finds a new meaning with each new telling" (qtd. in Mukherjee 2016). Doesn't every telling then become another travelling metaphor, the metaphor of a metaphor and so on in a layered network of resonating intertextualities?

To conclude, how do we situate Saurashtrani Rasdhar in a discussion of Translation Studies? If we go back to Gentzler's idea of translation as an always ongoing process of 'every' communication, Saurashtrani Rasdhar emerges as a negotiated retelling that embodies multiple encounters and border crossings. The encounter between Meghani and the people of Kathiawad, the encounter of two different classes, a retelling that not only spans different media but also enables the metaphorical border crossing between Saurashtra and Gujarat. Furthermore, the Rasdhar draws from the same cultural and linguistic socio-sphere as the oral narratives that it retells. Yet 
is also an instance that deconstructs the sense of regional homogeneity of Gujarat as a bounded region where Gujarati is spoken. It allows for spaces of alterity challenging prescriptions of linguistic and historical modes of being and remembering. It also legitimizes the spoken language in all its unstandardised variety as a valid mode of literature. In addition, it establishes an alternative history not just vis a vis the mainstream narrative of stereotypes but effectuates this by retaining forms of remembering by those at the margins, economically, culturally and socially.

Oral narratives unsettle anxieties of origin by being untraceable and unbordered- shapeshifting sources- sources taken in their true etymological sense of 'surgere' in French or to 'rise or to spring up,' a travelling metaphor characterized by its motility. The Rasdhar then needs to be read in its own context, not as a target tied in limbo with a source, but as an elusive telling whose story needs to be read and uncovered on its own terms and the multiple contexts that it straddles as a self-conscious early twentieth century piece of writing. I resort once more to Ramanujan to conclude the matter of shapeshifting sources and elusive targets befittingly with a folktale.

In a folktale told about Aristotle in Europe and about a philosopher in India, the philosopher meets a village carpenter who has a beautiful old knife, and asks him, "How long have you had this knife?" The carpenter answers, "Oh, this knife has been in our family for generations. We have changed the handle a few times and the blade a few times, but it is the same knife". Similarly, the structure of relations may remain constant, while all the cultural details change, as in a folktale that goes on changing from teller to teller. Any fixity, any reconstructed archetype, is a fiction, a label, a convenience" (Ramanujan 1988: 6). 


\section{References}

Desai, Shambhuprasad H. 'British Samrajya.' Saurashtrano Itishas, (Junagadh: Sorath Shikshan ane Sanskriti Sangh) 712-757.

Devy, Ganesh. 2010. Orality and Literacy. A Concise Companion to Postcolonial Literature, ed. by Shirley Chew and David Richards, 29-39. West Sussex: Blackwell Publishing Ltd.

Doshi, Yashwant et al. 2002. Sankalan: Saurashtrani Rasdhar -Vividh Lekhako. Meghanivivechansandoh Khand 1, ed. by Jayant Meghani, 216-220. Ahmedabad: Gurjar Granthratna Karyalaya.

Gentzler, Edwin. 2014. Translation without Borders. Translation: A

Transdisciplinary Journal 4. Online: http://translation.fusp.it/ articles/translation-without-borders.

Hess, Linda. 2015. Introduction. Bodies of Song,1-18. Oxford: Oxford University Press.

Meghani, Jhaverchand. 2014. Nivedan (Preface). Samagra Meghani Sahitya: Granth 9, ed. by Jayant Meghani,1-33. Ahmedabad: Gujarat Sahitya Akademy.

Meghani, Jhaverchand. 2014. Saurashtrani Rasdhar. Samagra Meghani Sahitya: Granth 9, ed. by Jayant Meghani. Ahmedabad: Gujarat Sahitya Akademy.

Meghani, Pinaki. 2002. Jhaverchand Meghani. Online: http:// www.jhaverchandmeghani.com/life-2.htm.

Merrill, Christi. 2009. Riddles of Belonging: India in Translation and Other Tales of Possession. Fordham: Fordham Univ Press.

Mukherjee, Oindrila. 2016. Why India's shape-shifting folk stories need to be read all over again. Bottom Shelf. Online: http://scroll.in/article/801280/why-these-shape-shifting- indianstories-need-to-be-read-all-over-again

Orsini, Francesca, and Katherine B. Schofield. 2015. Introduction. Tellings and Texts: Music, Literature and Performance in North India, 1-28. Cambridge: Open Book Publishers.

Preyer, G. and Mathias Bos. 2013. Introduction: Borderlines in the time of Globalisation. Borderlines in a Globalized World: New Perspectives in a Sociology of the World-System. Springer Science \& Business Media, ix-xviii, London: Kluwer Academic Publishers. 
Krupa Shah

Ramanujan, A. K. March, 1988. Who Needs Folklore? The Relevance of Oral Traditions to South Asian Studies,1-15. Manoa: University of Hawaii.

$* * *$ 